\title{
Especiales
}

\section{La violencia humana. ¿Qué hemos aprendido?}

\section{Human violence. What have we learned?}

\section{Enrique Vega Fernández}

Instituto Universitario "General Gutiérrez Mellado". Universidad Nacional de Educación a Distancia (UNED) Madrid. España.

\section{Recibido: 16-07-12}

Aceptado: 01-08-12

\section{Correspondencia}

Enrique Vega Fernández

Instituto Universitario General Gutiérrez Mellado

Universidad Nacional de Educación a Distancia (UNED)

C/ Princesa, n. ${ }^{\circ} 36$

28008 Madrid.

Tfno: (+34) 917580011

E-mail: evega@igm.uned.es

\section{Resumen}

El presente trabajo pretende aportar algunas reflexiones que permitan aproximarse al gran interrogante de por qué existen las guerras y siguen existiendo en el mundo de nuestros días. A través del concepto de cratotropismo, basado en la concepción de afán de dominio de Alfred Adler. Y de la traída: competencia ideológica o cultural, presión-resistencia económica, conflicto armado como último recurso, como modos de los enfrentamientos crato-eleuterotrópicos, basada en la concepción de la función moduladora del saber por los poderes sociales de Michel Foucault y en concepto marxista de propiedad.

Med Segur Trab (Internet) 2012; 58 (228) 186-193

Palabras clave: Guerra, violencia, cratotropismo, eleuterotropismo.

\begin{abstract}
The present work aims at inducing reflections upon how to approach the big question as why wars exist, and continue to exist, in the world we live in today. We proceed via the concept of cratotropism, based on Alfred Adler's conception of the thirst for power. And on the triad: ideological or cultural competition, financial pressure/resistance, and armed conflict as a last resource, as a means of confronting problems of a crato-eleuterotropic nature, and based on the conception of the modulating function of human knowledge in respect of Michel Foucault's "social powers" and the Marxist concept of property
\end{abstract}

Med Segur Trab (Internet) 2012; 58 (228) 186-193

Key words: war, violence, cratotropismo, eleuterotropismo. 


\section{INTRODUCCIÓN}

El objeto de este artículo es reflexionar sobre el siempre espinoso, pero al mismo tiempo tan atractivo, tema de la violencia humana, entendida como aquellas conductas, específicamente humanas, de agresión física que se podrían tildar de gratuitas desde un punto de vista adaptativo porque no responden, no son simplemente respuesta adaptativa, a aquellas necesidades que de no satisfacerse pueden poner en peligro la vida del individuo o la continuación de la especie: el alimento, el cobijo, la procreación, la protección de la prole, etcétera, sino que se desencadena en función de motivaciones situadas en niveles superiores de carácter no esencialmente adaptativo de la célebre pirámide motivacional de Maslow.

Su objetivo es intentar aportar algunas consideraciones que pudieran contribuir a esclarecer las sempiternas preguntas de si esta violencia específicamente humana y adaptativamente gratuita es un fenómeno de la estructura del cerebro o un fenómeno de la psique, del funcionamiento de esa estructura, de los modos en que se relacionan las diferentes y numerosas partes o elementos de esa estructura. Si es, por tanto, orgánica o inducida, genética o adquirida.

Y la forma en que pretende hacerse es repasando el proceso que permitió al autor de estas líneas finalizar su tesis doctoral, con la que pretendía acercarse a la comprensión de por qué existen las guerras y, sobre todo, por qué siguen existiendo en el mundo de nuestros días.

\section{Cratotropismo y eleuterotropismo}

Tenía que haber algún sustrato para la violencia humana gratuita y su señera manifestación, la guerra. Algo, en los humanos, que o no lo tuvieran las demás especies animales o lo tuvieran en un grado genéticamente mucho más débil. Y no podía ser la inteligencia o la razón, porque a lo que, al menos aparentemente, impulsan estas facultades es a lo contrario, a evitar ese derroche tantas veces innecesario y perjudicial de vidas, bienes, comodidades, bienestar, etcétera. Y buscando ese sustrato, me vino a la cabeza, no sabría responder cómo ni por qué, algo que yo había estudiado, o a lo mejor simplemente leído, cuando quince o veinte años antes había estudiado Psicología. Y. seguramente, porque ese algo me llamó la atención o me convenció, debí de guardarlo en algún rincón de mi subconsciente "por si algún día me hacía falta”. Y cuando finalmente afloró, tampoco sé exactamente por qué ni cómo, resultó ser algo que un psicoanalista heterodoxo llamado Alfred Adler había denominado "afán de poder" y "afán de dominio".

El punto de partida de Adler es la extraordinaria vulnerabilidad del cachorro humano comparado con el de las demás especies animales, que es infinitamente más inválido cuando nace que ellos y cuyo periodo de dependencia vital es también mucho más prolongado que el de cualquiera de ellos, siendo, sin embargo y al mismo tiempo, mucho más inteligente, es decir, mucho más capaz de relacionar causas y efectos y de crear pautas de conducta futura en función de estos nexos y relaciones. El resultado es que el cachorro humano tiene mucho tiempo para darse cuenta de que los adultos son capaces de hacer un buen número de cosas que él no puede hacer y que, sin embargo, le gustaría hacer y que, en consecuencia, tiene que depender de ellos para conseguirlas. Desde situaciones tan simples como alcanzar al pomo de una puerta para abrirla hasta decidir qué, cuándo y dónde se come. Para Adler, la consecuencia es doble. Por una parte, se desarrolla en el niño esa tendencia o afán de poder de la que hablábamos antes, de poder hacer lo que cree que los adultos pueden hacer de forma ilimitada y, sin embargo, él no puede. Y por otra, un cierto afán de dominio para que los demás (los adultos) hagan por él lo que él no puede hacer o le ayuden a hacerlo. El tipo de dominio que él inconscientemente percibe que tiene sobre los adultos, de los que consigue lo que quiere o necesita mediante sus llantos, sus mimos, su sumisión o sus gracias ${ }^{1}$.

Adquiridas estas tendencias en tan temprano estadio del desarrollo, se fijarán en su repertorio de tendencias de conducta por impronta. Es decir, el niño evolucionara 
reforzando unos patrones de conducta tendentes al afán de dominio, que tratará de reproducir más o menos consciente o inconscientemente, según los casos y las circunstancias, a lo largo de toda su vida. Unos patrones de conducta tendentes a utilizar a cuantos le rodean en su propio beneficio, para la satisfacción de sus necesidades y deseos. No con la intención de perjudicarles, sino simplemente para beneficiarse él ${ }^{2}$. Según Adler, ésta es una tendencia de la que no podremos librarnos en nuestra vida, al modo que los etólogos mostrarían posteriormente como las conductas adquiridas por impronta temprana quedan fijadas como tendencias de pautas de conducta toda la vida. Una impronta que si es posible es porque el ser humano tenga algún tipo de predisposición genética a adquirirla. En definitiva, una tendencia que constituirá uno de los motores permanentes de nuestra conducta ${ }^{3}$.

Y considerando que la conducta colectiva, en el fondo, sólo puede estar constituida por las actuaciones simultáneas o sucesivas, similares o complementarias, pero siempre coordinadas, conjuntas y sinérgicas de los diferentes individuos que conforman el grupo social actuante -aunque éste tenga también su propias leyes internas de funcionamientoy, por lo tanto, también inducida por las tendencias psíquicas que animen a éstos, creí posible extrapolar este concepto adleriano del afán dominio al ámbito de la política, entendida ésta como las diferentes formas en que puede organizarse la convivencia dentro de una determinada sociedad.

Y como el término de afán de dominio, aplicado al ámbito de la confrontación política por establecer las normas que deban regir la convivencia entre los distintos grupos sociales de una determinada sociedad, tiene en nuestras sociedades una connotación más bien peyorativa, que no se tiene por qué corresponder con algo que simplemente es una tendencia de comportamiento generalizada, no necesariamente perjudicial para los demás, preferí buscar un término neutro y que además sonara a neutro y, así, se me ocurrió el impronunciable neologismo "cratotropismo", derivado del griego kratos, poder, dominio, y del griego tropos, tendencia a, para designar la tendencia de cualquier grupo social a intentar utilizar a los demás grupos sociales en su propio beneficio, para la satisfacción de sus propios deseos, necesidades o aspiraciones ${ }^{4}$. No necesariamente para perjudicarles, sino simplemente para beneficiarse él.

Una vez concebido, me di cuenta de que el término y el concepto me permitían explicar ciertos fenómenos sociales universales. Por ejemplo, el cratotropismo podría ser, así, la base filogenética que explique la predisposición humana a manipular y modificar la naturaleza, probablemente el rasgo que mejor nos diferencia del resto de las especies animales. Lo que podría explicar por qué el hombre ha desarrollado la ciencia, la técnica y la tecnología, modificaciones y manipulaciones, en definitiva, de la naturaleza en su propio beneficio, para la satisfacción de sus deseos, necesidades y aspiraciones. Y podría ser la causa subyacente que explique por qué todos los tipos de sociedades conocidos han sido estratificados y jerarquizados, con unos seres humanos dominando a otros, utilizándolos en su propio beneficio, para la satisfacción de sus propios deseos, necesidades o aspiraciones, y con unos grupos sociales, sexos, clases, dinastías, naciones o imperios dominado a otros, utilizándolos en su propio beneficio, controlándolos para satisfacer sus propios deseos, necesidades y aspiraciones 5 .

Ahora bien, enseguida surgió la siguiente pregunta, ¿qué pasa con el cratotropismo de los dominados, de los subordinados, de los perjudicados? Que tenderá igualmente a poder manifestarse de forma permanente, a poder liberarse del displacer que su situación les provoca, al modo que el psicoanálisis nos muestra que los impulsos instintivos reprimidos tienden a expresarse para acabar con el displacer que su imposibilidad de manifestación produce al individuo.

En este sentido es en el que el cratotropismo podría explicar esa especie de tendencia histórica a la emancipación, a liberarse de la servidumbre que implica ser utilizado para el beneficio de otros, para la satisfacción de los deseos, necesidades o aspiraciones de otros, pudiendo explicar, al mismo tiempo, la suavización progresiva de las formas de dominación. Por poderosos y crueles que fueran los sátrapas de la antigüedad, su 
omnipotente dominio sobre sus súbditos ha acabado por desaparecer. Por divinos que se hayan considerado ciertos poderes políticos, la mayoría han acabado por no ser tenidos en cuenta. Por indispensables que se hayan considerado ciertas formas de autoritarismo patriarcal o religioso, hoy día han menguado hasta casi la extinción. Por superiores que se hayan considerado ciertas civilizaciones, culturas, razas o sexos, hoy día todo se ha relativizado. Ni la esclavitud, ni la servidumbre, ni el patriarcado, por ejemplo, volverán, al menos no en la forma en que se conocieron en las épocas en que se consideraban la ley natural.

Y es que el cratotropismo de los esclavos, de los siervos, de los trabajadores, de los indígenas, de las mujeres, de los hijos, de los fieles asustados, de los filósofos irritados o de las personas horrorizadas y asqueadas por ciertas formas de dominio, nunca dejó de pugnar por liberarse del displacer, intentando revertir la situación muchas veces y de muchas maneras, fracasando en múltiples ocasiones, pero consiguiendo poco a poco, de una forma más bien caótica, modificar estructuras familiares, sociales, políticas, religiosas o económicas en un sentido que parece seguir una dirección general histórica hacia la liberación, hacia la emancipación, hacia la igualdad, no exenta de retrocesos, desviaciones e, incluso, de creación de situaciones aún peores de la que se intentaba superar ${ }^{6}$.

En definitiva, el cratotropismo parece estar presente, incluso podría decirse, parece indispensable que esté presente, a modo de condición necesaria aunque no sea suficiente, para que puedan entenderse constantes históricas como la tendencia al dominio de los demás, la tendencia a la emancipación o la tendencia a la progresiva suavización de las formas de dominación, sin las cuales no parece posible comprender ni la historia ni la política, es decir, la evolución de las formas concretas en las que diferentes sociedades humanas han organizado y estructurado institucionalmente la convivencia ${ }^{7}$.

De modo que, a semejanza de como Adler pudo llegar a la conclusión de que el afán de poder y la tendencia al dominio son dos de los motores permanentes y universales, aunque indudablemente no los únicos, del comportamiento humano en relación con sus congéneres, puede llegarse a la conclusión de que el cratotropismo es uno de los motores permanentes y universales del comportamiento político colectivo y uno de los motores permanentes y universales que subyacen a la tendencia histórica de los pueblos a dominar a sus vecinos para que les "sirvan", como los diversos imperialismos, colonialismos o expansionismos que hemos conocido, y seguimos conociendo, parecen sugerir; pero también uno de los motores permanentes y universales de la tendencia histórica de los pueblos a liberarse de esta servidumbre, como los muchos casos de esfuerzos, luchas y sacrificios llevados a cabo en nombre de la liberación, la emancipación o la independencia de pueblos y poblaciones también nos sugieren, algunos muy recientes y en las portadas de nuestros medios de comunicación aún.

Unas tendencias, por tanto, con dos caras, la dominante y la emancipadora, que como las monedas o el dios Jano, pueden ser aparentemente contradictorias sin dejar de ser la misma moneda o el mismo dios. Razón por la cual y en aras exclusivamente del pragmatismo y de la claridad, pensé que sería más práctico diferenciarlas terminológicamente, dejando el neologismo "cratotropismo" para las tendencia de los grupos sociales en su actuar político a la utilización de los demás grupos sociales en su propio beneficio, para la satisfacción de sus deseos, necesidades y aspiraciones, y utilizar uno nuevo -no menos complicado de pronunciar- para la tendencia emancipadora o liberadora del cratotropismo, al que denominé "eleuterotropismo", derivado del griego eleutería, libertad, autonomía, y del griego, tropos, tendencia. Eleuterotropismo que, en el fondo, no es sino el cratotropismo -o la frustración de no poder ejercerlo, si se prefiere- de aquellos grupos sociales a los que la historia ha puesto, en un lugar y momento determinados, en situación dependiente o subordinada: tribus, pueblos, naciones, sexos, clases sociales o, incluso, culturas o civilizaciones enteras ${ }^{8}$.

Una concepción del devenir humano que nos permite entender la historia como una sucesión de enfrentamientos crato-eleuterotrópicos, en la que en cada lugar y momento histórico lo que vemos es el resultado de un enfrentamiento anterior del que han resultado 
el o los grupos sociales dominantes y el o los grupos sociales subordinados de ese momento. En el cual y entre los cuales se está volviendo a reproducir este enfrentamiento, en absoluto necesariamente violento, crato-eleuterotrópico. Y entender las guerras, fenómenos violentos y políticos, como la forma violenta, que no única, con la que se resuelven determinados enfrentamientos políticos entre tendencias cratotrópicas y eluterotrópicas, sea en el ámbito de las relaciones internacionales o lo sea en el de las confrontaciones entre diferentes sectores o comunidades dentro de un mismo país. Enfrentamientos violentos por razones de carácter político, es decir, de diferentes concepciones sobre como organizar la convivencia, que adquieren formas propias según la época y el tipo de sociedades o grupos sociales enfrentados implicados.

\section{Los modos del enfrentamiento crato-eleuterotrópico}

Lo que sí interesa volver a resaltar, aunque se ha procurado expresarlo repetidamente a lo largo de los anteriores comentarios, es que no hay que confundir enfrentamiento crato-eleuterotrópico con violencia. Lo cual parece dejarnos en el aire la siguiente pregunta. ¿Por qué en tantas situaciones de la historia parecen manifestarse con tan poca presencia estas confrontaciones crato-eleuterotrópicas, como si los grupos sociales más subordinados, más perjudicados, por la estructura social aceptasen de buen grado la situación que les ha tocado vivir?

Una posible explicación nos viene dada en gran medida por el filósofo francés Michael Foucault, que a las concepciones liberal y marxista del poder añadía la concepción del poder como modulador del saber. Según Foucault, en la concepción liberal, el poder político, es decir, la existencia de personas y grupos con capacidad de decidir sobre la forma en que debe estar organizada la convivencia en una determinada sociedad, es un producto de algún tipo de contrato social -voluntario o forzado, parcial o total- por el cual la mayoría de los individuos y grupos ceden esta posibilidad y capacidad a una persona, a un reducido número de personas o a un determinado grupo social. Mientras que en las concepciones marxistas, el poder se basa en el concepto de la propiedad, y especialmente de la propiedad de los medios de producción, es decir, en la capacidad de quien posee algo, cualquier cosa, material o inmaterial, de poder decidir sobre qué se hace con ella y cómo. Así, quien no "posee", sólo puede "vender" su capacidad de trabajo, mientras que quien "posee" (es decir, tiene la capacidad de decidir) puede repartir los beneficios de ese trabajo de forma inequitativa entre quien pone el trabajo (personas $o$ grupos sociales), que recibe lo indispensable para su supervivencia, y quien posee los medios (la propiedad), que puede así acumular cada vez más propiedad y, en consecuencia, poder, repitiendo el ciclo de forma indefinida. Para la concepción marxista, por tanto, el poder político tiene la función esencial de mantener el determinado régimen de propiedad (la determinada forma de organizar la convivencia entre las personas y los grupos sociales de una sociedad) que beneficia a los grupos sociales dominantes en ese momento ${ }^{9}$.

Lo que Foucault nos viene a decir es que ninguna de estas explicaciones por separado parece suficientemente convincente. Y que, además, no tienen por qué ser contradictorias, sino más bien complementarias, pero aun juntas, insuficientes. Él admite que las relaciones de poder tienen la forma de un contrato y tienen la función de mantener unas determinadas estructuras sociales basadas en la propiedad, pero la historia parece mostrar que tanto este origen como, sobre todo, su mantenimiento tienen unas veces el carácter de forzado, de impuesto, pero otras también el de voluntariamente aceptado. ¿Por qué? ¿Por qué el poder de ciertos grupos es, en tantísimas ocasiones, lugares y momentos, voluntariamente aceptado por los grupos dominados, subordinados, subalternos, etcétera, con niveles relativamente bajos de represión, en la mayoría de los casos de carácter meramente judicial?

La hipótesis de Foucault es que el poder, una vez alcanzado, tiene una inmensa capacidad de modelar el "saber". Saber, no entendido como sinónimo de "conocimientos", sino entendido como la capacidad de establecer en qué ámbitos se desarrollarán los conocimientos, qué será objeto de conocimiento, qué conceptos se han de utilizar, que 
técnicas han de emplearse, qué conocimientos son prioritarios o prestigiosos, qué personas deben saber, qué tipo de personas deben ser los productores de conocimiento, asimiladores de él o consumidores de sus resultados, etcétera ${ }^{10}$.

El "saber", en este sentido, no se refiere al conjunto de hechos, objetos, procesos y técnicas que han acontecido o se han inventado o descubierto, que es el cometido de los investigadores, de los científicos, de los académicos, de los intelectuales o de los técnicos, "trabajadores" después de todo, que solamente pueden "vender" su capacidad de trabajo intelectual. Ni siquiera se refiere tampoco solamente al conjunto de enunciados sobre ellos que hay que aceptar, sino al conjunto de reglas por el que una determinada sociedad va a discriminar lo verdadero de lo falso, lo bueno de lo malo, lo legítimo de lo ilegitimo, lo legal de lo ilegal, y la tricotomía obligatorio -autorizado o permitido- prohibido. Un conjunto de reglas que determina que técnicas o procedimientos son aceptables o no (el testimonio visual o el testimonio de un vídeo en un juicio, por ejemplo), o qué enunciados o discursos son aceptables o no (la guerra en nombre de los derechos humanos es aceptable, pero en nombre de una religión o de la superioridad racial, no, por ejemplo), o qué estructuras son aceptables o no (la democracia o la sharía como base legítima de la organización política de la convivencia) o qué mecanismos o instancias son aceptables o no (por ejemplo, sólo los médicos pueden curar y sólo los ingenieros y los arquitectos pueden construir, pero al mismo tiempo, sólo las universidades pueden decidir quien es médico, arquitecto o ingeniero) ${ }^{11}$. Piénsese solamente en lo que significa para el saber y los conocimientos de una sociedad, nacional o internacional, la resolución de determinadas cuestiones planteadas hoy día, como podrían ser, a título de ejemplos, células madre sí, células madre no, energía nuclear sí, energía nuclear no, memoria histórica sí, memoria histórica no, Educación para la ciudadanía o Ciudadanía y Constitución, patentes o genéricos, toros sí, toros no, etcétera.

Es a través de esta modulación del saber y de los conocimientos que producen comodidades (manipulaciones cratotrópicas de la naturaleza), tranquilidad (los relativos a la salud, por ejemplo), satisfacción intelectual (de la curiosidad instintiva del ser humano), etcétera: todo eso que llamamos progreso o desarrollo, como el poder -los poderes políticos, económicos, religiosos, etcétera, es decir, los grupos sociales dominantes en cada sociedad concreta- inducen a su aceptación voluntaria, a la aceptación voluntaria de la estructura social imperante de la que son beneficiarios, mediante la creación de la ideología y la mentalidad dominantes, en las que está inserto que todos esos beneficios del saber y de los conocimientos se deben precisamente a que existe esa determinada estructura social.

Lo que la concepción de Foucault nos permite es cerrar o redondear el círculo. Como consecuencia de unos determinados enfrentamientos crato-eleuterotrópicos previos, se crea una situación de alguna forma estratificada y jerarquizada de grupos sociales, países, culturas o lo que sea. En la que aquéllos que alcanzan el poder, es decir, su satisfacción cratotrópica más o menos plena -pero nunca total- procuran mantenerlo a través, por un lado, de la función creadora del poder: creación de la ideología y la mentalidad dominantes, en las que está inserto que todos los beneficios del saber y de los conocimientos se deben precisamente a que existe esa concreta estructura social, y a través, por otro lado, del régimen de propiedad imperante, que les beneficia y del que depende, en cierta forma, la supervivencia de los que no "poseen". Creándose así esa especie de contrato social, más o menos voluntaria y totalmente aceptado, sobre el que se basan las teorías liberales del poder. Una situación en la que, sin embargo, no dejarán de estar permanentemente pugnando las tendencias eleuterotrópicas de los grupos sociales más desfavorecidos, tratando de imponer ideologías y mentalidades alternativas y regímenes de propiedad (estructuras económicas) alternativos.

De modo que se estaría de nuevo en una situación de confrontación cratoeleuterotrópica, a dirimir, en consecuencia, a través de la competencia ideológica (o cultural, según el ámbito) y de presión-resistencia económica. Cuyos resultados, en algunas situaciones, como nos muestra la historia, y en tanto se den ciertas condiciones, pueden resultar inaceptables para alguna de las partes en litigio, que, en ese caso, eligen 
acudir a métodos más contundentes: a la violencia para imponer sus presupuestos, es decir, a la guerra o conflicto armado en el ámbito de estudio al que yo he intentado aplicar estas teorías, consideraciones y reflexiones ${ }^{12}$.

Todo lo cual me hizo llegar a entender por qué siempre ha habido guerras y las sigue habiendo. No porque el ser humano sea especialmente violento, que lo es la menos de las veces, sino porque es cratotrópico. Y solamente cuando no logra encauzar sus desavenencias en asuntos que considera vitales por los medios pacíficos de la competencia ideológica o cultural o de la presión-resistencia económica, entonces se acude, en última instancia, a los métodos violentos, sea a la guerra internacional (entre naciones), sea al conflicto armado interno o guerra civil.

Ahora bien, el cuándo estos grupos sociales, sean Estados soberanos o facciones enfrentadas dentro de un mismo país, llegan a considerar dichas desavenencias lo suficientemente vitales o importantes como para acudir a esta última instancia violenta, así como el cómo, las concretas formas violentas que utilicen para dirimirlas en cada caso concreto, es lo que se aprende. Lo que se deriva de cada una de las ideologías y mentalidades dominantes y alternativas imperantes. Por esto es por lo que en las sociedades democráticas, donde la capacidad de expresión y debate ideológicos y de confrontación de presión-resistencia social, económica y laboral es mucho más amplia, las posibilidades de que la confrontación social adquiera tintes violentos son mucho menores que en las sociedades autoritarias, donde estas capacidades están mucho más limitadas, tendiendo los poderes establecidos a mantener el statu quo con formas más violentas de represión y siendo las revueltas sociales, cuando se producen, asimismo mucho más violentas y destructivas. Y como la estructura de la sociedad internacional actual no es democrática, sino competitiva, de momento, parece haber pocas esperanzas de que no haya guerras.

\section{Las guerras de nuestros días}

Pero ninguna teoría puede considerarse plenamente aceptable, y en tanto no se demuestre lo contrario, si no es capaz de explicar al menos alguna porción de los fenómenos de la realidad en función de los cuales se elaboró. Y eso fue lo que se pretendió con la segunda parte de la tesis doctoral, en la que se analizó bajo el prisma de la triada competencia ideológica o cultural -presión-resistencia económica- conflicto armado como último recurso, las intervenciones armadas de los países occidentales en los Balcanes, en Afganistán y en Irak, la agresión armada a los países occidentales mediante acciones terroristas de lo que podríamos llamar la nebulosa al-Qaeda, y, como ejemplo de conflicto más reducido a un ámbito puramente interno, la sublevación zapatista en el Estado mexicano de Chipas de 1994.

Todo ello enmarcado en la concepción de que en la escena internacional de nuestros días se da la existencia de un "grupo social dominante" constituido por los países occidentales o desarrollados, que tratan de expandir e implantar en todo el mundo su ideología o mentalidad neoliberal, caracterizada por la combinación de un sistema político democrático y una estructura económica basada en la competencia comercial y, sobre todo, financiera cada vez más desregularizada. Frente a la cual, solamente se levantan de tiempo en tiempo descoordinadas ideologías o mentalidades alternativas, que o bien pretenden contraponerse a las influencias democratizadoras con objeto de preservar determinadas prebendas y privilegios de determinados grupos nacionales dominantes o bien tratan de liberarse de la dependencia y subordinación a las que se consideran sometidos por la liberalización financiera y comercial neoliberal dominante.

Y es en función de esta confrontación internacional crato-eleuterotrópica como se pretende explicar las injerencias democratizadoras occidentales en los Balcanes en la década de los noventa del pasado siglo $\mathrm{XX}^{13}$ y en Irak en el periodo 2003-2010 ${ }^{14}$, la "rebelión" yihadista frente a Occidente basada en una supuesta alienación del mundo musulmán ${ }^{15}$, que traerá como consecuencia directa la injerencia democratizadora occidental en Afganistán (2001-2014), iniciada en nombre de una supuesta legítima 
MEDICINA SEGURIDAD del trabajo

defensa frente a la agresión sufrida por Estados Unidos el 11 de septiembre de $2001^{16}$, y la rebelión zapatista del marginado mundo indígena chiapaneco justo el mismo día, 1 de enero de 1994, en el que entraba en vigor el Tratado de Libre Comercio entre México, Estados Unidos y Canadá, de marcado carácter neoliberal y supuestamente, en consecuencia, perjudicial para las débiles y precarias economías indígenas ${ }^{17}$.

\section{REFERENCIAS BIBLIOGRÁFICAS}

1. Adler A. Conocimiento del hombre. Madrid: Espasa Calpe; 1931:53 a 75.

2. Tobeña A. Anatomía de la agresividad humana. De la violencia infantil al belicismo. Barcelona: Galaxia Gutenberg; 2001:65.

3. Adler. Conocimiento del hombre. Op. cit.: 67.

4. Vega Fernández E. Los conflictos armados del neoliberalismo. Universidad Nacional de Educación a Distancia, Instituto Universitario General Gutiérrez Mellado. Madrid. 2010:32.

5. Vega. Los conflictos armados del neoliberalismo. Op. cit.: 32.

6. Vega. Los conflictos armados del neoliberalismo. Op. cit.: 34 .

7. Vega. Los conflictos armados del neoliberalismo. Op. cit.: 34 .

8. Vega. Los conflictos armados del neoliberalismo. Op. cit.: 34- 35.

9. Foucault M. Microfísica del poder. Madrid: Ediciones La Piqueta; 1992:133-137.

10. Foucault M. Estrategias de poder. Barcelona: Paidós; 1999:169-172.

11. Foucault. Microfísica del poder. Op. cit.: 187-188.

12. Vega. Los conflictos armados del neoliberalismo. Op. cit.: $45-50$ y 62-69.

13. Vega. Los conflictos armados del neoliberalismo. Op. cit.: 133-183.

14. Vega. Los conflictos armados del neoliberalismo. Op. cit.: 98-133.

15. Vega. Los conflictos armados del neoliberalismo. Op. cit.: 203-262.

16. Vega, Los conflictos armados del neoliberalismo, Op. cit.: 183-201.

17. Vega. Los conflictos armados del neoliberalismo. Op. cit.: 263-308.

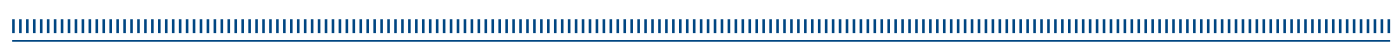

